This item was submitted to Loughborough's Research Repository by the author.

Items in Figshare are protected by copyright, with all rights reserved, unless otherwise indicated.

\title{
Motivation in physical education across the primary-secondary school transition
}

PLEASE CITE THE PUBLISHED VERSION

http://epe.sagepub.com/content/14/2/157.short

\section{PUBLISHER}

(c) North West Counties Physical Education Association and Sage Publications

\section{VERSION}

AM (Accepted Manuscript)

\section{LICENCE}

CC BY-NC-ND 4.0

\section{REPOSITORY RECORD}

Warburton, Victoria E., and Christopher M. Spray. 2019. "Motivation in Physical Education Across the Primarysecondary School Transition". figshare. https://hdl.handle.net/2134/11348. 
This item was submitted to Loughborough's Institutional Repository (https://dspace.lboro.ac.uk/) by the author and is made available under the following Creative Commons Licence conditions.

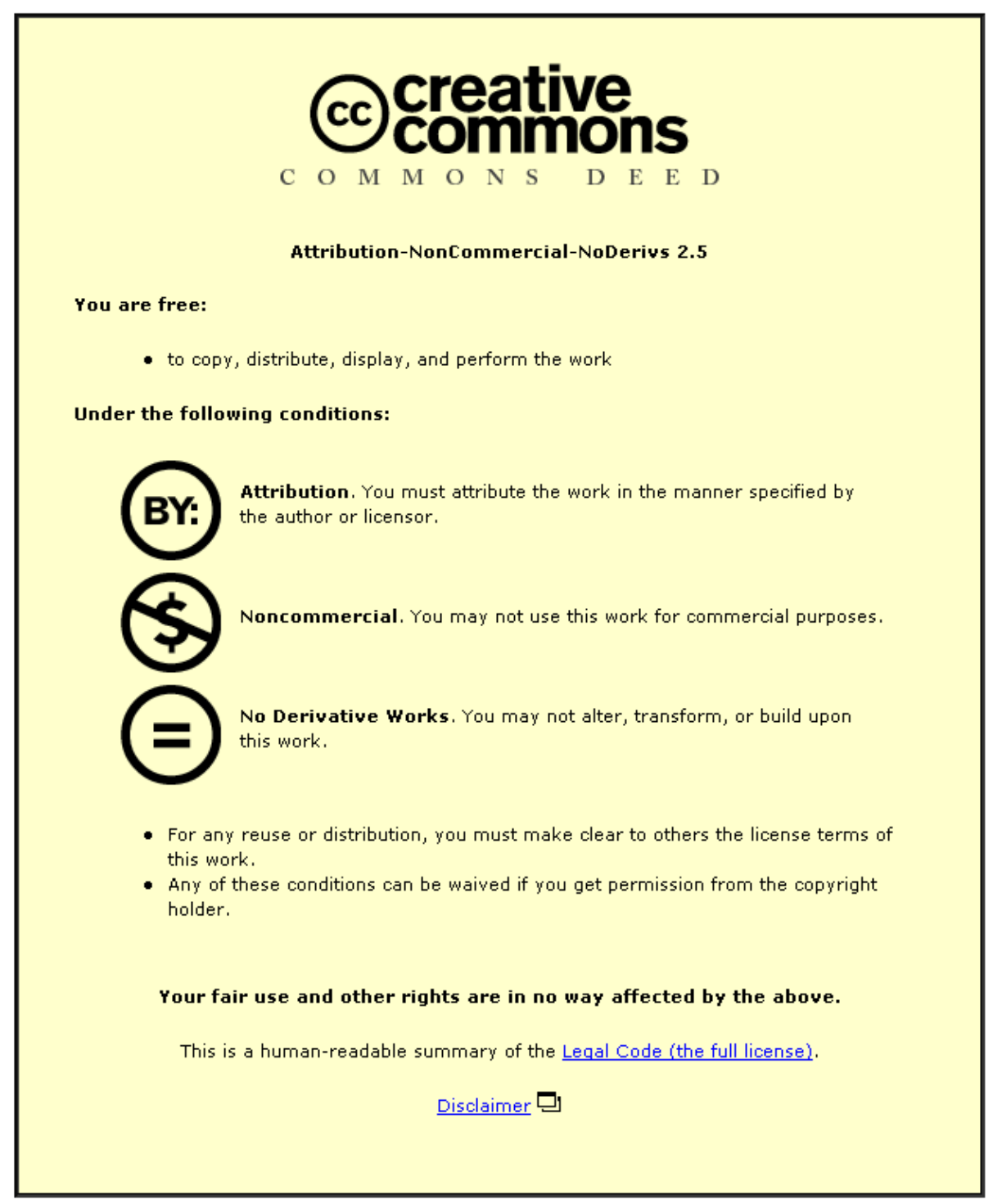

For the full text of this licence, please go to: http://creativecommons.org/licenses/by-nc-nd/2.5/ 
1 Running head: MOTIVATION IN PHYSICAL EDUCATION

2

3

4

5 Motivation in physical education across the primary-secondary school transition

6

7

8

9

10

11

12 Manuscript submitted: 07 December 2007

13 Revised manuscript submitted: 19 February 2008

14 Word count: 7701

15

16 


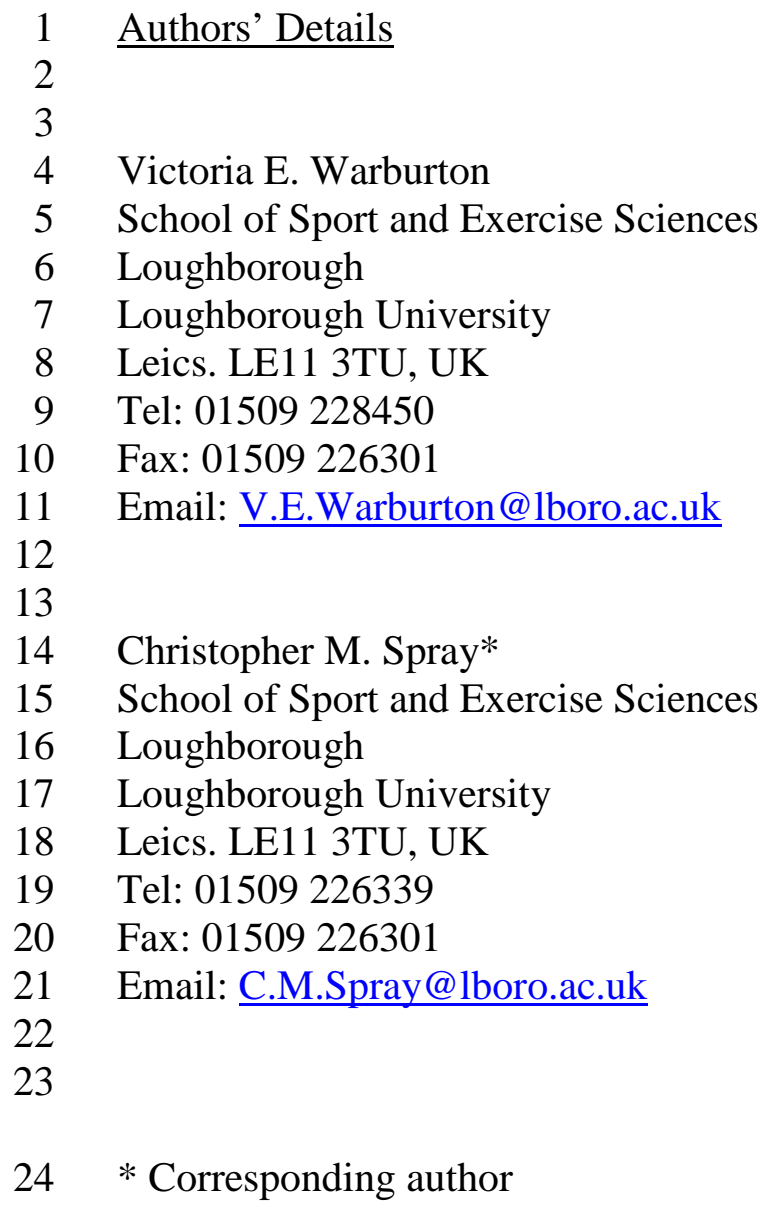


Abstract

2 The purpose of this study was to examine the temporal patterns of approach-

3 avoidance achievement goals, implicit theories of ability and perceived competence in

4 physical education across the transition from primary to secondary school. We also

5 evaluated the predictive utility of implicit theories and perceived competence with

6 regard to achievement goal adoption, and determined the moderating influence of

7 gender on temporal patterns and antecedent-goal relationships. One hundred and forty

8 pupils (mean age at start of study $=11.37$ years, $\mathrm{SD}=.28$ ) completed measures of

9 entity and incremental beliefs, perceived competence and goals on four occasions

10 during a 12-month period. Mastery-approach, performance-approach and

11 performance-avoidance goals, as well as entity and incremental beliefs, exhibited a

12 linear decline over time. Mastery-avoidance goals showed no significant change.

13 Girls exhibited a linear decline in perceived competence, whereas for boys, the

14 trajectory was curvilinear. Competence perceptions predicted initial scores, but not

15 rate of change, on mastery-approach and both types of performance goals.

16 Incremental beliefs predicted rate of change in mastery-approach goal adoption,

17 whereas entity beliefs were associated with changes in performance-avoidance goals

18 and initial scores on performance-approach goals. Limited differences between boys

19 and girls in these antecedent-goal relationships were observed. 
1 Key words: approach-avoidance achievement goals, implicit theories of ability,

2 perceived competence, physical education, primary-secondary school transition

3

4

5

6 


\section{Biographical Note}

2

3 Victoria Warburton is with the School of Sport and Exercise Sciences at 4 Loughborough University, UK.

5

6 Dr Christopher Spray is Senior Lecturer in the School of Sport and Exercise Sciences

7 at Loughborough University, UK.

8 
1 Motivation in Physical Education Across the Primary-Secondary School Transition The motivation of young people in school physical education (PE) has been a

3 popular topic of research in recent years. Much of this interest has been fuelled by a

4 concern that pupils' experiences of PE may not be positive, an awareness of

5 increasing sedentary behaviours among youth coupled with rising juvenile obesity,

6 and a recognition of the importance of the PE context in reaching all young children

7 and adolescents in laying a foundation for active, healthy lifestyles beyond school

8 (Biddle, Sallis \& Cavill, 1998). Researchers have utilised a wide array of theoretical

9 perspectives to further understanding of motivation. One of the most frequently

10 employed frameworks has been achievement goal theory (Elliot, 1999, 2005;

11 Nicholls, 1989). The present study adopted Elliot's contemporary hierarchical model

12 of approach-avoidance achievement motivation in identifying predictors of change in

13 pupils’ PE-based goals as they progressed from primary to secondary schooling.

14 Achievement Goals, Implicit Beliefs, and Perceived Competence

The work by Elliot (see Elliot, 1999, 2005; Elliot \& McGregor, 2001) and associates in the educational domain has sought to provide a comprehensive model of

17 achievement motivation through consideration of both approach and avoidance forms

18 of motivation, i.e., the need to achieve competence and the need to avoid

19 incompetence. Elliot's model amalgamates the approach and avoidance components

20 of need achievement theory with the mastery and performance goals of dichotomous

21 goal perspectives theory (see Nicholls, 1989) to propose a 2 x 2 achievement goal

22 framework. The four achievement goals proposed in this framework reflect different

23 representations of the definition and valence of competence. Specifically mastery-

24 approach goals focus on developing task- or self-referent competence, whereas 25 mastery-avoidance goals focus on avoiding developing task- or self-referent 
1 incompetence. Thus, pupils may strive to do their best on a class activity in the PE

2 lesson, or alternatively, their striving may stem from a concern that they are unable to

3 do the activity as well as they feel they can. Performance-approach goals focus on

4 demonstrating normative competence and performance-avoidance goals goals focus

5 on avoiding demonstrating normative incompetence. Thus, pupils aim to show they

6 are one of the best in the class at an activity, or alternatively, they are more concerned

7 with being worse at the activity than their classmates. In his theorising, Elliot

8 identifies a number of potential antecedents which are thought to represent the reasons

9 for individuals adopting these different goals in an achievement situation. These

10 include, for example, implicit theories of ability, competence expectancies, need for

11 achievement, fear of rejection, perception of the motivational climate, fear of failure,

12 and gender (see Elliot, 1999). In PE, the temporal relations between implicit theories

13 of ability and perceptions of competence with the four goals of the approach-

14 avoidance framework have received limited empirical attention. In the present study,

15 therefore, we focussed attention on the predictive utility of these antecedents whilst 16 controlling for possible gender effects. Implicit theories of ability refer to the stability or malleability of human

18 attributes and behaviours. Initially, research extensively examined implicit theories in 19 the educational domain with regard to the effect of children's views about the stability 20 or malleability of their intelligence on educational achievement (see Dweck, 1999).

21 This research has supported the existence of two implicit theories of ability, termed 22 incremental and entity theories. The endorsement of incremental beliefs leads 23 individuals to view personal attributes and behaviours as being malleable, controllable 24 qualities that are increasable through learning. On the other hand, the endorsement of 25 entity beliefs leads individuals to view personal attributes and behaviours as a fixed, 
1 stable capacity (quantity) that cannot be improved. As such, individuals are described

2 as incremental theorists or entity theorists depending on which view of human

3 attributes and behaviours they endorse.

Research in the educational and physical domains has shown that entity and

5 incremental beliefs are associated with different achievement goals. Holding

6 incremental beliefs leads to the adoption of mastery goals, whereas the endorsement

7 of entity beliefs leads to the adoption of performance goals (Biddle et al., 1999, 2003;

8 Cury et al., 2002; Dweck \& Bempechat, 1983; Dweck \& Leggett, 1988; Lintunen et

9 al., 1999; Ommundsen, 2001; Sarrazin et al., 1996). Particularly in the PE and sport

10 contexts, however, previous research has adopted mainly cross-sectional designs that

11 limit the strength of conclusions regarding causality and direction of influence.

12 Elliot's model (Elliot, 1999) also suggests that perceptions of competence

13 antecede achievement goal adoption. High perceptions of competence are expected to

14 be associated with approach goals (both mastery and performance), while low

15 perceptions of competence are expected to be associated with both types of avoidance

16 goals. Research in education and PE domains has found support for these links

17 between perceptions of competence and approach-avoidance achievement goals (e.g.,

18 Cury et al., 2002; Elliot \& Church, 1997). However, there is a dearth of longitudinal

19 research that speaks to the patterns of change in competence perceptions and

20 approach-avoidance achievement goal adoption over time. Studies of dichotomous

21 achievement goals and perceptions of competence in PE utilising cross-sectional age

22 comparisons have suggested, however, that older pupils report lower task (mastery)

23 orientation and perceived competence than younger pupils (Digelidis \& Papaioannou, 24 1999).

25 Primary-Secondary School Transition 
One of the key periods in a child's school career that is likely to impact on

2 their experiences, motivation and achievement in all school subjects, including PE, is

3 the transition from primary to secondary school. This transition occurs during a key

4 developmental period for pupils and can be a difficult time, both academically and

5 socially (Zeedyk et al., 2003). In the educational domain, the Observational Research

6 and Classroom Learning Evaluation (ORACLE) project assessed pupils' enjoyment,

7 motivation and achievement across the transfer from primary to secondary school in

8 the UK (see Delamont \& Galton, 1986; Galton \& Wilcocks, 1983). This research

9 found that as much as forty percent of pupils failed to make the expected progress in

10 the year immediately after transfer in mathematics, reading and language skills. In

11 addition, while pupils' motivation and enjoyment increased in the first term after

12 transfer, they had declined by the end of the school year to levels below those

13 observed in primary school prior to transfer. A recent replication of the ORACLE

14 project found a similar pattern of results (Hargreaves \& Galton, 2002).

15 Research by Eccles and colleagues in the US (Eccles \& Harold, 1991; Eccles

16 et al., 1989, 1993a\&b; Jacobs et al., 2002; Wigfield et al., 1991) has utilised the

17 expectancy-value theory of achievement motivation (Eccles et al., 1983; Wigfield \&

18 Eccles, 1992) to examine the influence of the transition from primary school to

19 secondary school on achievement motivation ${ }^{1}$. Of particular interest are the findings

20 on sport competency beliefs. While there appeared to be a general downward

21 trajectory in sport competency beliefs over a child's school career, this decline

22 accelerated following the transition to secondary school (Jacobs et al., 2002). The

23 greatest declines in sport competency beliefs were observed immediately after the

24 transition (Eccles et al., 1989; Marsh, 1989; Wigfield et al., 1991). 
Several studies have utilised the dichotomous achievement goal perspective

2 (Dweck, 1986, 1990; Nicholls, 1989) to examine pupils’ achievement motivation in

3 mathematics and English across the primary to secondary school transition (e.g.,

4 Anderman \& Anderman, 1999; Anderman \& Midgley, 1997). Pupils reported lower

5 endorsement of mastery goals, greater adoption of performance goals, and a decline in

6 perceived academic competence in both subjects after the transfer.

$7 \quad$ The Present Study

To our knowledge, there has been no published research that has examined

9 pupil's implicit theories of ability, perceived competence and approach-avoidance 10 goals across the transition from primary to secondary school in the PE context. The

11 aim of the present research was to examine temporal patterns among key achievement 12 motivation variables and to examine the predictive utility of implicit theories of 13 ability and perceived competence to approach-avoidance achievement goal adoption 14 as pupils progressed from Year 6 in primary school to Year 7 in secondary school. 15 Moreover, the effects of gender on goals, goal antecedents, and antecedent-goal 16 relationships were examined.

17 Previous research has revealed no consistent pattern of gender differences in 18 the endorsement of incremental and entity theories of ability and approach-avoidance 19 goal adoption. Limited evidence suggests that academically able girls are more likely 20 than able boys to endorse an entity theory of ability (Leggett, 1985). However, other 21 evidence suggests there are no gender differences in the endorsement of incremental 22 and entity beliefs (Freedman-Doan et al., 2000). In education, Anderman and 23 colleagues (Anderman \& Anderman, 1999; Anderman \& Midgley, 1997) have shown 24 that boys are more likely to endorse performance goals than girls. This finding 25 complemented other studies which identified gender differences to exist in the 
1 endorsement of achievement goals (Ryan et al., 1997; Roeser et al., 1997). However,

2 a review of research on gender and motivation in the educational domain concluded

3 that there was 'no clear pattern of gender differences in students' achievement goal

4 orientations' (Meece et al., 2006, p. 360).

5 Gender differences in competency beliefs, which emerge early in a child's

6 school career, have been shown to remain across the transition to secondary school 7 and through late adolescence (Eccles \& Harold, 1991; Eccles et al., 1993b; Jacobs et 8 al., 2002, Wigfield et al., 1991). Boys report higher sport competency beliefs than

9 girls. In PE-based studies in the UK, girls have been found to be over-represented in 10 clusters that can be described as 'poorly motivated' i.e., characterised by weak goal 11 orientations, incremental beliefs, and perceived competence, or 'amotivated' i.e., 12 characterised by low mastery orientation, incremental beliefs, perceived competence 13 and high entity beliefs. On the other hand, boys tend to be over-represented in 'highly 14 motivated' groups i.e., characterised by strong goal orientations, incremental and 15 entity beliefs, and perceived competence (see, for example, Wang \& Biddle, 2001).

16 Based on previous research, we anticipated that pupils would, on average, decline in their perceptions of competence in PE across the transition to secondary school (Jacobs et al., 2002). Perceptions of competence were predicted to be higher

19 for boys than girls at all assessment points (Jacobs et al., 2002; Wang \& Biddle, 20 2001). Further, we hypothesised that higher perceptions of competence would predict 21 initial status (when pupils were in Year 6) and rate of change (throughout Year 7) in 22 mastery-approach and performance-approach goals. On the other hand, lower 23 competence perceptions would be associated with initial status and rate of change in 24 mastery-avoidance and performance-avoidance goals. Moreover, we expected 25 incremental beliefs to predict initial status and rate of change in mastery-approach and 
1 mastery-avoidance goals, whereas entity beliefs were hypothesised to predict initial

2 status and rate of change in both types of performance goals (Cury et al., 2002; Elliot,

3 1999, 2005). Finally, due to the present research being the first, to our knowledge, to

4 assess implicit theories of ability and approach-avoidance achievement goals in PE

5 across the transfer to secondary school, we decided not to propose specific a priori

6 hypotheses for their temporal patterns. Similarly, given that previous research has not

7 revealed consistent differences between boys and girls in the adoption of implicit

8 theories and achievement goals, we chose not to posit hypotheses for this aspect of the 9 study.

Method

\section{Participants}

Male ( $\underline{\mathrm{n}}=68)$ and Female $(\underline{\mathrm{n}}=72)$ participants from Year 6 of three primary

13 schools in East England, United Kingdom participated in the research. These schools

14 were selected on the basis that they were feeder schools to a specific secondary school

15 where arrangements for post transfer data collection had already been agreed. At the 16 start of the research (wave 1 ), participants were aged 10 or 11 years $(\underline{M}=11.37, \underline{S D}=$ $17 \quad 0.28$ years).

18 Procedures

Ethical approval for the research procedures was obtained from the relevant

20 institutional body. These procedures complied with the guidelines of the British

21 Psychological Society. Permission for conducting the research was sought from the 22 head teacher at each of the primary schools and the secondary school to which 23 participants were transferring at the end of the school year. Parental consent was 24 obtained through distribution of letters prior to data collection. Following an 25 introduction to the purpose of the research, informed assent was given from all 
1 participants through the completion of a willingness to participate form. Any child

2 who did not have parental consent or give their informed assent for participation in

3 the research was withdrawn from all data collection procedures. All procedures took

4 place in a normal curriculum lesson. Participants were assured that all information

5 collected would be anonymous and would remain confidential. They were provided

6 with the opportunity to ask any questions before the questionnaire was administered.

7 An explanation of how to complete each section of the questionnaire was given. Each

8 participant responded to an anonymous multi-section questionnaire which took

9 approximately 20 minutes to complete. These procedures were repeated at 3, 6 and

1012 months following wave 1 . At wave 1 , the participants were nearing the end of

11 Year 6 of primary school and at waves $2-4$, participants had transferred into Year 7

12 of secondary school.

13 Measures

14 Each participant completed a multi-section questionnaire that collected the

15 following information.

16 Personal Details. This section of the questionnaire contained items relating to form 17 group, date of birth, gender, age, and primary school. Because the questionnaires 18 were anonymous and repeated measurements were to be taken, this information 19 allowed participants to be identified at subsequent data points.

20 Goal Adoption. Goal adoption was assessed using the Achievement Goals

21 Questionnaire for Sport (Conroy et al., 2003). Students responded to 12 items on a 22 seven-point Likert scale that ranged from not at all true of me (1) to very much like 23 me (7). Three items assessed each type of goal. Sample items included, 'It is 24 important for me to perform as well as I possibly can' (mastery-approach), 'I am often 25 concerned that I may not perform as well as I can perform' (mastery-avoidance), 'It is 
1 important to me to do well compared to others' (performance-approach), 'I just want

2 to avoid performing worse than others' (performance-avoidance).

3 Implicit Theories of Ability. Participants' conceptions of the nature of ability in sport

4 and PE were assessed using the 'Conceptions of the Nature of Athletic Ability

5 Questionnaire version 2' (CNAAQ-2, Biddle et al, 2003). Twelve items, assessing

6 four sub-scales which reflect different representations of the nature of ability, were

7 answered on a five-point Likert scale that ranged from strongly disagree (1) to

8 strongly agree (5). Sample items include 'It is difficult to change how good you are at

9 sport/PE' (stable), 'To be good at sport/PE you need to be naturally gifted' (gift),

10 'You need to learn and to work hard to be good at sport/PE' (learning), 'If you put

11 enough effort into it, you will always get better at sport/PE' (improvement). The

12 CNAAQ-2 posits a hierarchical factor structure, with stable and gift sub-scales

13 underpinning a higher order entity belief, and learning and improvement sub-scales

14 underpinning a higher order incremental belief. In the present study, we were

15 interested only in the two higher-order dimensions of implicit beliefs.

16 Perceived Competence. Pupils' sense of competence in PE was assessed using six 17 items answered on a 5-point Likert scale that ranged from strongly disagree (1) to 18 strongly agree (5). Example items included 'I am often able to successfully complete 19 the activities I am set in PE', 'I can perform tasks and skills in PE better than I used 20 to', and 'I am better at PE than others in my class'.

$21 \quad$ Data Analysis

First, we examined the extent and pattern of missing data across the four

23 intervals, and determined whether associations were evident between missing data and

24 the substantive variables under investigation. Data were missing as a consequence of 25 normal absences on the days of questionnaire administration. There were no 
1 significant associations between number of missed measurement occasions and initial

2 scores on implicit beliefs, perceived competence or goals. Because the amount of

3 missing data was small, we chose not to replace missing scores.

All main analyses were carried out using MLwiN (version 2.0, Rasbash et al.,

5 2005). ${ }^{2}$ MLwiN is specifically designed to analyse multilevel data (see Singer \&

6 Willett, 2003). In the present study, repeated measurement occasions were nested

7 within individuals. Moreover, implicit beliefs and perceptions of competence served

8 as time-varying predictors of achievement goal adoption (to explain within- and

9 between-person variability), whereas gender acted as a time-invariant predictor (to

10 explain between-person variance only). A series of models was examined to address

11 the current research questions. In these models, time was centred at wave 1 and the 12 time-varying predictors were grand-mean centred (Singer \& Willett, 2003). Model A

13 represented an unconditional means model which was used to assess the amount of

14 between-person and within-person variance in the variables under investigation. The

15 variance estimates produced from this model allow the intra-class correlation 16 coefficient to be calculated. The intra-class correlation coefficient indicates how 17 much of the total variation in the dependent variable is attributable to differences 18 between individuals and provides the justification for using multilevel methods of 19 data analysis. In the present research, the intraclass correlation coefficients were as 20 follows: perceived competence (0.61), incremental beliefs (0.42), entity beliefs $(0.36)$ 21 and mastery-approach (0.57), mastery-avoidance (0.28), performance-approach (0.52) 22 and performance-avoidance goals (0.47). These coefficients suggested that significant 23 amounts of variance remained that could potentially be explained by within- and 24 between-person predictors. 
Model Bi represented an unconditional growth model which examined the

2 initial status and linear rate of change for each of the variables under investigation.

3 Model Bii represented a nonlinear growth model which examined whether there were

4 quadratic changes over time in the variables under investigation. Both linear and

5 quadratic representations of time were included in this model. ${ }^{3}$

$6 \quad$ Model C represented an uncontrolled effects model. These models separately

7 examined whether gender, incremental beliefs, entity beliefs or perceived competence

8 predicted either initial status or rate of change in students' approach-avoidance

9 achievement goal adoption. In line with theoretical propositions, perceived

10 competence and incremental beliefs were entered as predictors of initial status and

11 rate of change in mastery- approach and avoidance goals. Similarly, perceived

12 competence and entity beliefs were entered as predictors of initial status and rate of

13 change in performance- approach and avoidance goals (Dweck, 1986, 1999; Elliot,

14 1999). In addition, an uncontrolled effects model examined the effect of gender on

15 the initial status and rate of change in incremental and entity beliefs and perceptions 16 of competence.

The final model (Model D) represented a controlled effects model. These models examined the effects of implicit theories of ability or perceived competence on pupil's initial status and rates of change in approach-avoidance achievement goal 20 adoption while controlling for the effects of pupils' gender.

Model fit was assessed through examination of the deviance statistic of the

22 model $(-2 \log L)$ and established whether adding predictors of initial status and the

23 rate of change significantly improved model fit. ${ }^{4}$ In order to present the most 24 parsimonious models, only those main effects and interaction effects for models in 
1 which a significant improvement in model fit was observed are reported (Cohen,

2 Cohen, West \& Aiken, 2003).

Results

\section{$4 \quad$ Preliminary Analyses}

Descriptive statistics and internal consistency estimates were computed for

6 each subscale at each wave of measurement and are presented in Table 1 along with

7 the average internal consistency estimates across time. Mean scores for all subscales

8 except for mastery-avoidance and perceived competence showed a decline over the

9 course of the investigation. At wave 1, the observed alpha values for three subscales

10 (mastery-approach, performance-avoidance and incremental beliefs) were below 0.70 .

11 At wave 2, only the mastery-approach scale failed to exhibit acceptable levels of 12 internal consistency, whereas all subscales showed acceptable reliability at waves 3

13 and 4. The average alpha values for each subscale across waves of measurement 14 exceeded 0.70.

15

\section{INSERT TABLE 1 ABOUT HERE}

\section{$\underline{\text { Main Analyses }}$}

Temporal patterns. Results from the unconditional growth model (Model Bi) showed that the mean level (intercept) of each variable under investigation was significantly different from zero at the first wave of measurement. Of the four achievement goals, mastery-approach goals (5.50) had the highest intercept and mastery-avoidance goals (4.33) the lowest intercept at wave 1. Incremental beliefs (4.15) were more highly endorsed than entity beliefs (2.62). Examination of the rate of change (slope) of all variables revealed that mastery-approach $(\beta=-0.08, p<$ 
1 .001), performance-approach $(\beta=-0.21, p<.001)$ and performance-avoidance goals

$2(\beta=-0.24, p<.001)$, incremental beliefs $(\beta=-0.05, p<.05)$ and entity beliefs $(\beta=-$

3 0.07, $p<.01$ ) evidenced significant change over time. Specifically, these variables

4 showed a linear decline in scores across waves 1 to 4 . Perceived competence

5 exhibited a nonlinear rate of change over time, which was indicated by a significant

6 improvement in model fit when a quadratic term was added to the model $\left(\Delta X^{2}(4)=\right.$

7 13.23, $p<.05$ ) (Model Bii). A small decline in perceived competence was observed

8 immediately after transfer to secondary school, followed by a plateau during the

9 remainder of Year 7. Finally, mastery-avoidance goals showed no significant change

10 over time $(\beta=0.01, p>.05)$.

11 Gender differences in goals, perceptions of competence and ability beliefs. At

12 wave 1 , gender (coded $0=$ female, $1=$ male) was a positive predictor of mastery-

13 approach $(\beta=0.85, p<.001)$, performance-approach $(\beta=0.94, p<.001)$ and

14 performance-avoidance goals $(\beta=0.46, p<.05)$ and perceived competence $(\beta=0.67$,

$15 p<.001)$. Boys reported higher scores on these variables than girls at wave 1 and at

16 all subsequent measurement occasions. The interaction between gender and quadratic

17 time $(\beta=0.09, p<.05)$ was a significant predictor of perceived competence. As

18 illustrated in Figure 1, perceived competence was predicted to show a linear decline

19 over time for girls, while for boys the trajectory revealed a small decrease on transfer

20 to secondary school with a slower decline during Year 7 and a small increase at the

21 end of the school year. No other main effects, nor interaction effects between gender

22 and time, were observed $(p>.05)$. 
Predicting change in mastery-approach goal adoption. In Model C,

2 perceptions of competence $(\beta=0.87, p<.001)$ were found to positively predict

3 mastery-approach goal adoption at the start of the research, but had no effect on the

4 rate of change over time $(p>.05)$. In contrast, incremental beliefs had no effect on

5 the adoption of mastery-approach goals in Year $6(p>.05)$, but positively predicted

6 the rate of change in mastery-approach goal adoption across Year 7 ( $\beta=0.20, p<$ $7 \quad .001)$

We then repeated the analyses but controlling for pupils’ gender (Model D).

9 Results are presented in Table 2. For a one-point difference in perceived competence, 10 average initial mastery-approach goal adoption was 0.89 higher; for a one-point 11 difference in incremental beliefs, average rate of change in mastery-approach goal 12 adoption during Year 7 was 0.20 higher.

INSERT TABLE 2 ABOUT HERE

Predicting mastery-avoidance goal adoption in Year 6. In Model C, perceptions of competence and incremental beliefs had no significant effect on mastery-avoidance goal adoption at the end of Year $6(p>.05)$. However, as shown in Table 3, when controlling for gender (Model D), perceptions of competence positively predicted mastery-avoidance goal adoption. For a one-point difference in perceived competence, average initial mastery-avoidance goal adoption was 0.36 higher. Controlling for perceived competence, boys reported lower scores on mastery-avoidance goals than girls when at primary school.

\section{INSERT TABLE 3 ABOUT HERE}


Predicting change in performance-approach goal adoption. The addition of

3 either perceptions of competence or entity beliefs to the model predicting

4 performance-approach goals (Model C) revealed that both perceived competence $(\beta=$

$5 \quad 0.80, p<.001)$ and entity beliefs $(\beta=0.24, p<.05)$ predicted performance-approach

6 goal adoption in Year 6. However, they had no effect on the rate of change across

$7 \quad$ Year 7 ( $p>.05)$. When controlling for gender (Model D), for a one-point difference in

8 perceived competence, average initial performance-approach goal adoption was 0.77

9 higher; for a one-point difference in entity beliefs, average rate of change in 10 performance-approach goal adoption during Year 7 was 0.33 higher (see Table 4).

11

INSERT TABLE 4 ABOUT HERE

Predicting change in performance-avoidance goal adoption. In Model C, perceptions of competence $(\beta=0.51, p<.001)$ were found to predict performanceavoidance goal adoption at the start of the research, but had no effect on the rate of change $(p>.05)$. In contrast, entity beliefs had no significant effect on the adoption of performance-avoidance goals in Year $6(p>.05)$, but positively predicted the rate of change in performance-avoidance goal adoption across Year $7(\beta=0.13, p<.05)$. When controlling for gender (Model D), for a one-point difference in perceived competence, average initial performance-avoidance goal adoption was 0.61 higher; for a one-point difference in entity beliefs, average rate of change in performanceavoidance goal adoption during Year 7 was 0.13 higher (see Table 5). 
Discussion

Physical education provides a unique setting in the school curriculum for examining achievement motivation. The focus on physical competence as well as cognitive competence sets it apart from many other subjects in the school curriculum.

6 The striving for competence or striving to avoid incompetence is pertinent in PE as the abilities of pupils are unambiguous, constantly on public display and can be easily and regularly evaluated by the self and others. The present research sought to identify

9 temporal patterns among key achievement motivation variables in PE across the 10 transfer from primary to secondary school. The predictive utility of implicit theories 11 of ability and perceived competence in explaining approach-avoidance achievement 12 goal adoption over this transitional education period were examined. Finally, we 13 sought to determine the influence of gender on these motivational processes.

Temporal Patterns of Achievement Goals, Beliefs and Perceived Competence 2005; Elliot \& McGregor, 2001) were endorsed in the present sample as mean scores at each measurement occasion were above the scale mid-point. However, consistent with previous research in the physical domain, mastery-approach goals were the most strongly endorsed on all four occasions (Conroy \& Elliot, 2004; Conroy et al., 2003; Wang, Biddle \& Elliot, 2007).

The present research provides the first insight into the temporal patterning of approach-avoidance achievement goal adoption in the PE context from primary to secondary school. Following the transfer to secondary school, there was a linear

24 decline in the adoption of mastery-approach, performance-approach and performance25 avoidance goals during Year 7. The analysis also revealed that the adoption of 
1 mastery-avoidance goals was stable over the study period. In PE, young children's

2 concern with, and their striving to avoid, self- and task-referenced failure appears to

3 be persistent, at least during the period studied in the current investigation. This may

4 be of concern to teachers of PE as it shows a focus of their students on incompetence

5 and failure. The salience of mastery-avoidance goals in PE across the primary-

6 secondary transition supports previous cross-sectional research on adolescents in the

7 physical domain (Conroy et al., 2003; Wang, et al., 2007). Initial studies suggest that

8 young people may experience motivational difficulties as a result of pursuing

9 mastery-avoidance goals (e.g., Conroy et al., 2006).

In the present study, a decline in both types of performance goals was

11 observed over the transition from primary to secondary school. This contrasts with

12 evidence in the educational domain which examined dichotomous achievement goals

13 over a transition (Anderman \& Anderman, 1999; Anderman \& Midgley, 1997).

14 Further research which examines pupils' motivation in Year 8 of secondary school

15 and beyond is needed to establish whether this decline is temporary. Moreover, this

16 research should identify the situational predictors of pupils' approach-avoidance

17 performance goal adoption, which were unexplored in the present study.

At all four measurement occasions, individuals in the current sample held the

19 view that sport ability can be improved and developed through learning more strongly

20 than the view that sport ability is a fixed, stable quantity. This finding is consistent

21 with previous research in the physical domain (Biddle et al., 2003; Cury et al., 2002).

22 The temporal analysis of implicit theories of ability revealed a linear decline in the

23 endorsement of incremental and entity beliefs across the primary-secondary transition.

24 Future work needs to identify, not only the causal predictors of such changes, but also

25 their motivational ramifications for young people in PE. 
Mean scores for perceptions of competence in the present sample were above

2 the scale mid-point at all four measurement occasions, although highest when pupils

3 were at primary school. A nonlinear trajectory emerged for perceptions of

4 competence across the primary-secondary school transition for the total sample.

5 Perceptions of competence showed a decline when transferring to secondary school,

6 and continued to decline at a slower rate in the early part of Year 7 before reaching a

7 plateau at the end of the year. When pupils transfer to secondary school, they become

8 members of a new and larger reference group, in which they make judgements about

9 their ability relative to others. The addition of new members to this reference group

10 alters the standard for being one of the best at PE, which may make pupils feel less

11 able than when based in primary school classes. The transfer to secondary school also

12 results in the pupils being taught by specialist PE teachers, rather than generalist

13 primary teachers. The PE teachers may promote new criteria or standards by which

14 individuals judge their competence. Pupils may feel less able to meet the new

15 standards immediately after transfer and so feel less competent than when

16 participating in PE at primary school. Pupils may also be introduced to a variety of 17 new activities which they are less confident of mastering. These situational 18 characteristics may serve to reduce perceptions of competence at the start of 19 secondary school.

20 However, as pupils progress through Year 7, they complete additional units of

21 work which build on the tasks and skills learnt at the beginning of the year, and so 22 may feel more able to meet the demands of PE. Pupils have also established 23 themselves within their new, larger reference groups and adjusted to the standards of 24 competence promoted by PE teachers. These aspects may halt the decline in 25 perceptions of competence throughout Year 7. 
1 Predicting Approach-Avoidance Achievement Goals

Consistent with theoretical predictions, individuals who endorsed the view that

3 ability in PE is a fixed, stable quantity were more likely, initially, to adopt goals

4 focused on normative competence (Dweck, 1986, 1999). In addition, over time,

5 higher entity beliefs were positively associated with performance-avoidance goal

6 adoption. Interventions that serve to minimise the development of entity beliefs

7 among pupils in PE may counteract potential concern with demonstrating normative

8 incompetence during Year 7. Consequently, pupils will be less likely to experience

9 the negative outcomes linked with this form of achievement striving, i.e., low levels

10 of performance and intrinsic motivation, high levels of anxiety and worry (Elliot \&

11 Church, 1997; Elliot \& Conroy, 2005; Elliot \& McGregor, 2001).

Incremental beliefs were shown to predict increases in mastery-approach goals

13 over the course of the study. In other words, endorsing the view that ability can be

14 improved and developed through learning led to an increased adoption, over time, of

15 goals which focused on developing task- and/or self-referenced competence. In

16 accordance with previous research in which mastery-approach goals were associated

17 with the most positive outcomes in achievement situations (e.g., persistence, effort,

18 intrinsic motivation, self-regulated learning; Elliot \& Church, 1997; Elliot \&

19 McGregor, 2001; Middleton \& Midgley, 1997), the present work adds further support

20 to the importance of developing and sustaining in pupils a belief that physical skills

21 can be acquired and improved through learning and practice.

22 In line with theoretical propositions and previous research in the physical

23 domain, perceptions of competence were positively associated with both types of

24 approach goals (Cury et al., 2002; Wang et al., 2007). However, counter to

25 theoretical propositions (Elliot, 1999, 2005), performance-avoidance goals were 
1 positively related with perceptions of competence. Previous research in the PE

2 context has also found this relationship to be positive (Wang et al., 2007). The ability

3 of young children to discern between the subtleties of performance-approach and

4 performance-avoidance achievement striving may account for this finding (see Urdan

5 \& Mestas, 2006). Further research, adopting both quantitative and qualitative

6 approaches, is needed to ascertain children's and adolescents' comprehension of these

7 constructs in PE.

Although perceived competence was positively linked with mastery-approach,

9 performance-approach and performance-avoidance goals on all measurement

10 occasions, there was no effect on changes in goal adoption. It would appear that

11 changes in perceived competence have little impact on the dynamics of achievement 12 goal striving among pupils starting secondary school. Based on present results,

13 interventions in the physical domain that wish to increase pupils' adoption of mastery14 approach goals may be more effective if they target other antecedents e.g., 15 incremental ability beliefs.

16 The Influence of Gender

In the present study, uncontrolled effects models revealed that gender was not associated with variability in incremental and entity beliefs about ability, either in 19 primary school, or during the first year of secondary school. However, gender 20 differences in perceived competence, along with mastery-approach, performance21 approach and performance-avoidance goal adoption, appeared to be established by the 22 time pupils left primary school, and these differences remained during Year 7. This 23 suggests that future research designed to capture changes in children's sense of 24 competence and goal adoption in PE (and associated predictors) should be conducted 25 during the primary school years. We need to ascertain the individual and 
1 environmental characteristics that lead boys to feel more competent in primary school

2 PE class and report greater striving to demonstrate self- and normatively-referenced

3 competence (and avoid normatively-referenced incompetence). In line with previous literature in the physical domain, boys reported higher

5 perceptions of competence than girls at all measurement occasions (Eccles, Wigfield,

$6 \quad$ Harold \& Blumenfeld, 1993; Marsh, 1998). The trajectory for boys evidenced a small

7 decline over the transfer to secondary school, a slower decline in the early part of

8 Year 7, and a small increase at the end of Year 7. This is encouraging as boys'

9 perceptions of competence appeared to recover over the course of Year 7 from the

10 decline observed immediately after transfer to secondary school. For girls, it would

11 seem that perceptions of competence exhibit a linear decline. Further work is 12 necessary to determine if the decline in girls' perceived competence continues through 13 Year 8.

The significant findings relating antecedents to goals in uncontrolled effects 15 models remained when controlling for gender e.g., the effects of perceived 16 competence on adoption of both types of approach goals in Year 6 and the effects of entity beliefs on the rate of change over time in performance-avoidance goals.

18 However, some interesting insights emerged. For example, when controlling for 19 perceived competence, gender appeared to be associated with mastery-avoidance 20 goals (in favour of girls). Controlling for gender, perceived competence positively 21 predicted initial mastery-avoidance goal adoption. Moreover, although initial 22 performance-avoidance goal adoption was predicted by perceived competence, 23 change in performance-avoidance goal scores over the course of the study was 24 explained by gender. Controlling for perceived competence, boys were estimated to 25 report greater performance-avoidance goal adoption over time than girls. 
In conclusion, the present research highlights some important changes in motivation in PE classes as children transition from primary to secondary school.

3 These changes appear, on the whole, to be suggestive of less adaptive motivation

4 profiles e.g., reduced competence perceptions, lowered incremental views about

5 ability, and lowered mastery-approach goal adoption. However, we also found a

6 reduction in performance-avoidance goal striving over time, which could arguably be 7 interpreted as adaptive. Longer-term longitudinal research, involving multiple 8 primary and secondary schools, is required to enhance the generalisability of results,

9 and in particular, to investigate important environmental predictors of achievement 10 motivation at the teacher, class and school levels. The focus of the current study was 11 restricted to the influence of personal antecedents impacting on goal pursuit. Future 12 studies should determine the combined influence of implicit ability beliefs and 13 competence perceptions. Work is also needed to identify the cognitive, affective and 14 behavioural outcomes linked to changing motivational processes. We would 15 especially recommend that research efforts are pursued to delineate the temporal 16 patterning of pupils' motivational perceptions and outcomes in PE over their entire school careers. Present findings suggest, for example, that the effects of perceived competence on goal pursuit may occur earlier in pupils' schooling than the effects of implicit ability beliefs. Unlike perceived competence, the influence of incremental views of ability on mastery-approach goals, and entity views on performance21 avoidance goals, appeared to emerge during the first year of secondary school rather than during primary school. These empirical findings require verification in larger samples, but ultimately may inform the timing of targeted interventions. Such

24 endeavours will collectively assist primary teachers and specialist physical educators to optimise motivation in PE across the transition from primary to secondary school. 
$2{ }^{1}$ In the present paper, the phrase 'primary to secondary school' will be used

3 throughout, even when referring to research based in the United States on the transfer

4 from elementary to junior high school.

52 Confirmatory factor analyses were also conducted at each time point on the scales

6 measuring achievement goals, beliefs, and perceived competence but results are not

7 reported here. The findings supported previous research in the physical domain which

8 has found the AGQ-S and CNAAQ-2 to be valid and reliable measures of approach-

9 avoidance achievement goals and implicit theories of ability respectively (Biddle et

10 al., 2003; Conroy et al., 2003). Given that we specifically designed perceived

11 competence items for the present study, we conducted CFA to establish reliability and

12 factorial validity of the perceived competence scale. Results supported a one factor

13 model (e.g., Time 1: $\chi^{2}=1.97$ (6df), NNFI $=1.073$, CFI $=1.000$, SRMR $=.017$,

14 RMSEA $=.000(\mathrm{CI}=.000-.037)$. Factor loadings across all time points ranged

15 from .514 - .847. Further details can be obtained from the first author.

$16{ }^{3}$ Only perceived competence exhibited nonlinear change over time. Model C for 17 perceived competence therefore developed from the unconditional nonlinear growth 18 model. Model C for all other variables developed from the unconditional linear 19 growth model.

$20{ }^{4}$ Details of the deviancy statistics pertaining to model modifications can be obtained 21 from the first author. 
References

2 Anderman, L. H. and Anderman, E. M. (1999) 'Social Predictors of Changes in Students' Achievement Goal Orientations', Contemporary Educational Psychology 24(1): 21-37.

Anderman, E. M. and Midgley, C. (1997) 'Changes in Achievement Goal

Biddle, S. J. H., Wang, C. K. J., Chatzisarantis, N. L. D. and Spray, C. M. (2003) 'Motivation for Physical Activity in Young People: Entity and Incremental Beliefs About Athletic Ability', Journal of Sports Sciences 21(12): 973-989.

Cohen, J., Cohen, P., West, S. G. and Aiken, L. S. (2003). Applied Multiple Regression/Correlation Analysis for the Behavioral Sciences. Lawrence Erlbaum Associates, Mahwah, NJ.

Conroy, D. E. and Elliot, A. J. (2004) 'Fear of Failure and Achievement Goals in Sport: Addressing the Issue of the Chicken and the Egg', Anxiety, Stress and 
1 Conroy, D. E., Elliot, A. J. and Hofer, S. M. (2003) 'A 2 x 2 Achievement Goals Questionnaire for Sport: Evidence for Factorial Invariance, Temporal Stability, and External Validity', Journal of Sport \& Exercise Psychology 25(4): 456-476.

Conroy, D. E., Kaye, M. P. and Coatsworth, J. D. (2006) 'Coaching Climates and the Destructive Effects of Mastery-Avoidance Achievement Goals on Situational Motivation', Journal of Sport \& Exercise Psychology 28(1): 69-92.

Cury, F., Da Fonseca, D., Rufo, M. and Sarrazin, P. (2002) 'Perceptions of Competence, Implicit Theory of Ability, Perception of Motivational Climate, and Achievement Goals: A Test of the Trichotomous Conceptualization of Endorsement of Achievement Motivation in the Physical Education Setting', Perceptual and Motor Skills 95: 233-244.

Delamont, S. and Galton, M. (1986) Inside the Secondary Classroom. Routledge \& Kegan Paul, London.

Digelidis, N., \& Papaioannou, A. (1999) 'Age-Group Differences in Intrinsic Motivation, Goal Orientations and Perceptions of Athletic Competence, Physical Appearance and Motivational Climate in Greek Physical Education', Scandinavian Journal of Medicine \& Science in Sports, 9(6): 375-380.

Dweck, C. S. (1986) 'Motivational Processes Affecting Learning', American Psychologist 41(10): 1040-1048.

Dweck, C. S. (1990) 'Self-theories and goals: Their role in motivation, personality, and development', in R. Dienstbier (ed) Nebraska Symposium on Motivation 1990. Perspectives on Motivation, pp. 199-235.University of Nebraska Press, Lincoln, NE. 
1 Dweck, C. S. (1999) Self Theories: Their Role in Motivation, Personality, and Development. Psychology Press, Philadelphia, PA.

Dweck, C. S. and Bempechat, J. (1983) 'Children's theories of intelligence: Consequences for learning', in S.G. Paris, G.M. Olson and H.W. Stevenson (eds) Learning and Motivation in the Classroom, pp. 239-256. Lawrence Erlbaum Associates, Hillsdale, NJ.

Dweck, C. S. and Leggett, E. L. (1988) 'A Social-Cognitive Approach to Motivation and Personality', Psychological Review 95(2): 256-273.

Eccles, J. S., Adler, T. F., Futterman, R., Goff, S. B., Kaczala, C. M., Meece, J. L. and Midgley, C. (1983) 'Expectancies, values and academic behaviours', in J.T. Spence (ed) Achievement and Achievement Motives, pp. 75-146. WH Freeman, San Francisco.

Eccles, J. S. and Harold, R. D. (1991) 'Gender Differences in Sport Involvement: Applying the Eccles' Expectancy-Value Model', Journal of Applied Sport Psychology 3: 7-35.

Eccles, J. S., Midgley, C., Wigfield, A., Buchanan, C. M., Reuman, D., Flanagan, C. and Maciver, D. (1993a) 'Development During Adolescence: The Impact of Stage-Environment Fit on Young Adolescents’ Experiences in Schools and in Families', American Psychologist 48(2): 90-101.

Eccles, J. S., Wigfield, A., Flanagan, C. A., Miller, C., Reuman, D. A. and Yee, D. (1989) 'Self-Concepts, Domain Values, and Self-Esteem: Relations and Changes at Early Adolescence', Journal of Personality 57(2): 283-310.

Eccles, J. S., Wigfield, A., Harold, R. D. and Blumenfeld, P. (1993b) 'Age and Gender Differences in Children's Self and Task Perceptions During ElementarySchool', Child Development 64(3): 830-847. 
1 Elliot, A. J. (1999) 'Approach and Avoidance Motivation and Achievement Goals', Educational Psychologist 34(3): 169-189.

Elliot, A. J. (2005) 'A conceptual history of the achievement goal construct', in A.J. Elliot and C.S. Dweck (eds) Handbook of Competence and Motivation, pp. 55-72. Guildford Press, New York.

Elliot, A. J. and Church, M. A. (1997) 'A Hierarchical Model of Approach and Avoidance Achievement Motivation', Journal of Personality and Social Psychology 72(1): 218-232.

Elliot, A. J. and Conroy, D. E. (2005) 'Beyond the Dichotomous Model of Achievement Goals in Sport and Exercise Psychology', Sport \& Exercise Psychology Review 1(1): 17-25.

Elliot, A. J. and McGregor, H. A. (2001) 'A 2 x 2 Achievement Goal Framework', Journal of Personality and Social Psychology 80(3): 501-519.

Freedman-Doan, C., Wigfield, A., Eccles, J. S., Blumenfeld, P., Arbreton, A. and Harold, R. D. (2000) 'What am I Best at? Grade and Gender Differences in Children's Beliefs About Ability Improvement', Journal of Applied Developmental Psychology 21(4): 379-402.

Galton, M. and Willcocks, J. (1983) Moving From the Primary School. Routledge and Kegan Paul, London.

Hargreaves, L. and Galton, M. (2002) Transfer From the Primary Classroom: 20 Years on. Routledge-Falmer, London.

Jacobs, J. E., Lanza, S., Osgood, D. W., Eccles, J. S. and Wigfield, A. (2002) 'Changes in Children's Self-Competence and Values: Gender and Domain Differences Across Grades One Through Twelve', Child Development 73(2): 509-527. 
1 Leggett, E. L. 1985 Children's Entity and Incremental Theories of Intelligence: Relationship to Achievement Behaviour. Paper presented at the annual meeting of the Eastern Psychological Association, March, Boston.

Lintunen, T., Valkonen, A., Leskinen, E. and Biddle, S. J. H. (1999) 'Predicting Physical Activity Intentions Using a Goal Perspectives Approach: A Study of Finnish Youth', Scandinavian Journal of Medicine \& Science in Sports 9: 344352.

Marsh, H. W. (1989) 'Age and Sex Effects in Multiple Dimensions of Self-Concept: Preadolescence to Early Adulthood', Journal of Educational Psychology 81(3): 417-430.

Marsh, H. W. (1998) 'Age and Gender Effects in Physical Self-Concepts for Adolescent Elite Athletes and Nonathletes: A Multicohort-Multioccasion Design', Journal of Sport \& Exercise Psychology 20(3): 237-259.

Meece, J. L., Glienke, B. B. and Burg, S. (2006) 'Gender and Motivation', Journal of School Psychology 44(5): 351-373.

Middleton, M. J. and Midgley, C. (1997) 'Avoiding the Demonstration of Lack of Ability: An Underexplored Aspect of Goal Theory', Journal of Educational Psychology 89(4): 710-718.

Nicholls, J. G. (1989) The Competitive Ethos and Democratic Education. Harvard University Press, Cambridge, MA.

Ommundsen, Y. (2001) 'Pupils' Affective Responses in Physical Education Classes: The Association of Implicit Theories of the Nature of Ability and Achievement Goals', European Physical Education Review 7(3): 219-242.

Rasbash, J., Steele, F., Browne, W. and Prosser, B. (2005) A User's Guide to MLwiN Version 2.0. University of Bristol, United Kingdom. 
1 Roeser, R. W., Midgley, C. and Urdan, T. C. (1996) 'Perceptions of the School . 5 Psychological Environment and Early Adolescents' Psychological and Behavioral Functioning in School: The Mediating Role of Goals and Belonging', Journal of Educational Psychology 88(3): 408-422.

Ryan, A. M., Hicks, L. and Midgley, C. (1997) 'Social Goals, Academic Goals, and Avoiding Seeking Help in the Classroom', Journal of Early Adolescence 17(2): 152-171.

Sarrazin, P., Biddle, S., Famose, J. P., Cury, F., Fox, K. and Durand, M. (1996) 'Goal Orientations and Conceptions of the Nature of Sport Ability in Children: A Social Cognitive Approach', British Journal of Social Psychology 35: 399414.

Singer, J. D. and Willet, J. B. (2003) Applied Longitudinal Data Analysis: Modeling Change and Event Occurrence. Oxford University Press, New York.

Urdan, T. and Mestas, M. (2006) 'The Goals Behind Performance Goals', Journal of Educational Psychology 98(2): 354-365.

Wang, C. K. J. and Biddle, S. J. H. (2001) 'Young People's Motivational Profiles in Physical Activity: A Cluster Analysis', Journal of Sport \& Exercise Psychology 23(1): 1-22.

Wang, C. K. J., Biddle, S. J. H. and Elliot, A. J. (2007) 'The 2 x 2 Achievement Goal Framework in a Physical Education Context', Psychology of Sport and Exercise 8(2): 147-168.

Wigfield, A. and Eccles, J. S. (1992) 'The Development of Achievement Task Values: A Theoretical Analysis', Developmental Review 12: 265-310. 
1 Wigfield, A., Eccles, J. S., Maciver, D., Reuman, D. A. and Midgley, C. (1991) 'Transitions During Early Adolescence: Changes in Children’s DomainSpecific Self-Perceptions and General Self-Esteem Across the Transition to Junior-High School', Developmental Psychology 27(4): 552-565.

Zeedyk, M. S., Gallacher, J., Henderson, M., Hope, G., Husband, B. and Lindsay, K. (2003) 'Negotiating the Transition From Primary to Secondary School: Perceptions of Pupils, Parents and Teachers', School Psychology International 24(1): 67-79. 
Table 1: Descriptive Statistics and Internal Consistency Estimates at Each Wave of Measurement

\begin{tabular}{|c|c|c|c|c|c|c|c|c|c|c|c|c|c|c|}
\hline & \multirow[b]{2}{*}{ Range } & \multicolumn{3}{|c|}{ Wave 1} & \multicolumn{3}{|c|}{ Wave 2} & \multicolumn{3}{|c|}{ Wave 3} & \multicolumn{3}{|c|}{ Wave 4} & \multirow[b]{2}{*}{$\begin{array}{l}\text { Average } \alpha \\
\text { Waves 1-4 }\end{array}$} \\
\hline & & M & SD & $\alpha$ & M & SD & $\alpha$ & M & SD & $\alpha$ & M & SD & $\alpha$ & \\
\hline $\begin{array}{l}\text { Mastery- } \\
\text { Approach }\end{array}$ & $1-7$ & 5.51 & 1.25 & .67 & 5.46 & 1.20 & .63 & 5.33 & 1.29 & .75 & 5.31 & 1.34 & .74 & .70 \\
\hline $\begin{array}{l}\text { Mastery- } \\
\text { Avoidance }\end{array}$ & $1-7$ & 4.34 & 1.71 & .78 & 4.34 & 1.63 & .78 & 4.29 & 1.53 & .75 & 4.39 & 1.48 & .80 & .78 \\
\hline $\begin{array}{l}\text { Performance- } \\
\text { Approach }\end{array}$ & $1-7$ & 4.59 & 1.71 & .83 & 4.27 & 1.73 & .88 & 4.06 & 1.63 & .89 & 3.98 & 1.69 & .88 & .87 \\
\hline $\begin{array}{l}\text { Performance- } \\
\text { Avoidance }\end{array}$ & $1-7$ & 5.06 & 1.53 & .62 & 4.72 & 1.62 & .80 & 4.57 & 1.55 & .77 & 4.35 & 1.71 & .83 & .76 \\
\hline $\begin{array}{l}\text { Perceived } \\
\text { Competence }\end{array}$ & $1-5$ & 4.01 & 0.74 & .81 & 3.68 & 0.85 & .85 & 3.78 & 0.83 & .85 & 3.64 & 0.90 & .89 & .85 \\
\hline $\begin{array}{l}\text { Incremental } \\
\text { Beliefs }\end{array}$ & $1-5$ & 4.18 & 0.65 & .68 & 4.05 & 0.71 & .72 & 4.03 & 0.71 & .76 & 4.03 & 0.71 & .78 & .74 \\
\hline $\begin{array}{l}\text { Entity } \\
\text { Beliefs }\end{array}$ & $1-5$ & 2.61 & 0.85 & .71 & 2.57 & 0.89 & .75 & 2.49 & 0.86 & .77 & 2.40 & 0.75 & .71 & .74 \\
\hline
\end{tabular}


Table 2: Controlled Effects Models Predicting Mastery-Approach Goal Adoption

\begin{tabular}{|c|c|c|c|c|c|c|}
\hline \multirow{2}{*}{\multicolumn{2}{|c|}{ Fixed Effects }} & \multicolumn{2}{|c|}{ Perceived Competence } & & \multicolumn{2}{|c|}{ Incremental Beliefs } \\
\hline & & Estimate & SE & & Estimate & SE \\
\hline \multirow{3}{*}{$\begin{array}{l}\text { Initial } \\
\text { status }\end{array}$} & Intercept & 5.240 & $0.076 * * *$ & Intercept & 5.076 & $0.124 * * *$ \\
\hline & PC & 0.892 & $0.061^{* * *}$ & Incremental $^{\mathrm{a}}$ & 0.169 & 0.102 \\
\hline & Gender & 0.351 & $0.106^{* *}$ & Gender & 0.807 & $0.177 * * *$ \\
\hline \multirow{3}{*}{$\begin{array}{l}\text { Rate of } \\
\text { change }\end{array}$} & & & & Intercept & 0.002 & 0.043 \\
\hline & & & & Incremental & 0.198 & $0.062 * * *$ \\
\hline & & & & Gender & -0.147 & $0.047 * *$ \\
\hline
\end{tabular}

Note: Intercept describes the coefficient for initial status and rate of change in MAp goals for a girl of average perceived competence/incremental beliefs. PC/Incremental describes the coefficient for the differential in initial status or rate of change for a one-unit difference in perceived competence/incremental beliefs controlling for the effect of gender. Gender describes the coefficient for the differential in initial status and rate of change between girls and boys controlling for the effect of perceived competence/incremental beliefs.

${ }^{a}$ In this model, the main effect of incremental beliefs was retained even though it was non-significant because when it was removed there was a significant decline in model fit.

$* * p<0.01 * * * p<0.001$ 
Table 3: Controlled Effects Models Predicting Mastery-Avoidance Goal Adoption

\begin{tabular}{lccc}
\hline & \multicolumn{2}{c}{ Perceived Competence } \\
\cline { 3 - 4 } \multicolumn{2}{l}{ Fixed Effects } & Estimate & SE \\
\hline Initial & Intercept & 4.542 & $0.116^{* * *}$ \\
status & PC & 0.355 & $0.093^{* * *}$ \\
& Gender & -0.349 & $0.167^{*}$ \\
\hline
\end{tabular}

Note: Intercept describes the coefficient for initial status in MAv goals for a girl of average perceived competence. PC describes the coefficient for the differential in initial status for a one-unit difference in perceived competence controlling for the effect of gender. Gender describes the coefficient for the differential in initial status between girls and boys controlling for the effect of perceived competence.

${ }^{*} p<0.05 * * * p<0.001$ 
Table 4: Controlled Effects Models Predicting Performance-Approach Goal Adoption

\begin{tabular}{|c|c|c|c|c|c|c|}
\hline \multirow{2}{*}{\multicolumn{2}{|c|}{ Fixed Effects }} & \multicolumn{2}{|c|}{ Perceived Competence } & & \multicolumn{2}{|c|}{ Entity Beliefs } \\
\hline & & Estimate & SE & & Estimate & SE \\
\hline \multirow{3}{*}{$\begin{array}{l}\text { Initial } \\
\text { status }\end{array}$} & Intercept & 4.110 & $0.149 * * *$ & Intercept & 4.047 & $0.164 * * *$ \\
\hline & PC & 0.767 & $0.091 * * *$ & Entity & 0.331 & $0.087 * * *$ \\
\hline & Gender & 0.595 & $0.195 * *$ & Gender & 0.951 & $0.211 * * *$ \\
\hline $\begin{array}{l}\text { Rate of } \\
\text { change }\end{array}$ & Intercept & -0.131 & $0.047 * *$ & Intercept & -0.192 & $0.049 * * *$ \\
\hline
\end{tabular}

Note: Intercept describes the coefficient for initial status and rate of change in PAp goals for a girl of average perceived competence/entity beliefs. PC/Entity describes the coefficient for the differential in initial status for a one-unit difference in perceived competence/entity beliefs controlling for the effect of gender. Gender describes the coefficient for the differential in initial status between girls and boys controlling for the effect of perceived competence/entity beliefs.

$* * p<0.01 * * * p<0.001$ 
Table 5: Controlled Effects Models Predicting Performance-Avoidance Goal Adoption

\begin{tabular}{|c|c|c|c|c|c|c|}
\hline \multirow{2}{*}{\multicolumn{2}{|c|}{ Fixed Effects }} & \multicolumn{2}{|c|}{ Perceived Competence } & & \multicolumn{2}{|c|}{ Entity Beliefs } \\
\hline & & Estimate & SE & & Estimate & SE \\
\hline \multirow{3}{*}{$\begin{array}{l}\text { Initial } \\
\text { status }\end{array}$} & Intercept & 4.913 & $0.115^{* * *}$ & Intercept & 4.698 & $0.149 * * *$ \\
\hline & PC & 0.614 & $0.087 * * *$ & Entity $^{\mathrm{a}}$ & 0.121 & 0.115 \\
\hline & & & & Gender & 0.626 & $0.197 * *$ \\
\hline \multirow{3}{*}{$\begin{array}{l}\text { Rate of } \\
\text { change }\end{array}$} & Intercept & -0.270 & $0.056 * * *$ & Intercept & -0.216 & $0.046 * * *$ \\
\hline & & & & Entity & 0.129 & $0.059 *$ \\
\hline & Gender & 0.208 & $0.073^{* *}$ & & & \\
\hline
\end{tabular}

Note: Intercept describes the coefficient for initial status and rate of change in PAv goals for a girl of average perceived competence/entity beliefs. PC/Entity describes the coefficient for the differential in initial status and rate of change for a one-unit difference in perceived competence/entity beliefs controlling for the effect of gender. Gender describes the coefficient for the differential in initial status and rate of change between girls and boys controlling for the effect of perceived competence/entity beliefs.

${ }^{a}$ In this model the main effect of entity beliefs was retained even though it was non-significant because when it was removed there was a significant decline in model fit.

${ }^{*} p<0.05 * * p<0.01 * * * p<0.001$ 
Motivation in Physical Education 41

Figure Captions

Figure 1: Temporal pattern of perceived competence in physical education among boys and girls across the primary-secondary school transition. 


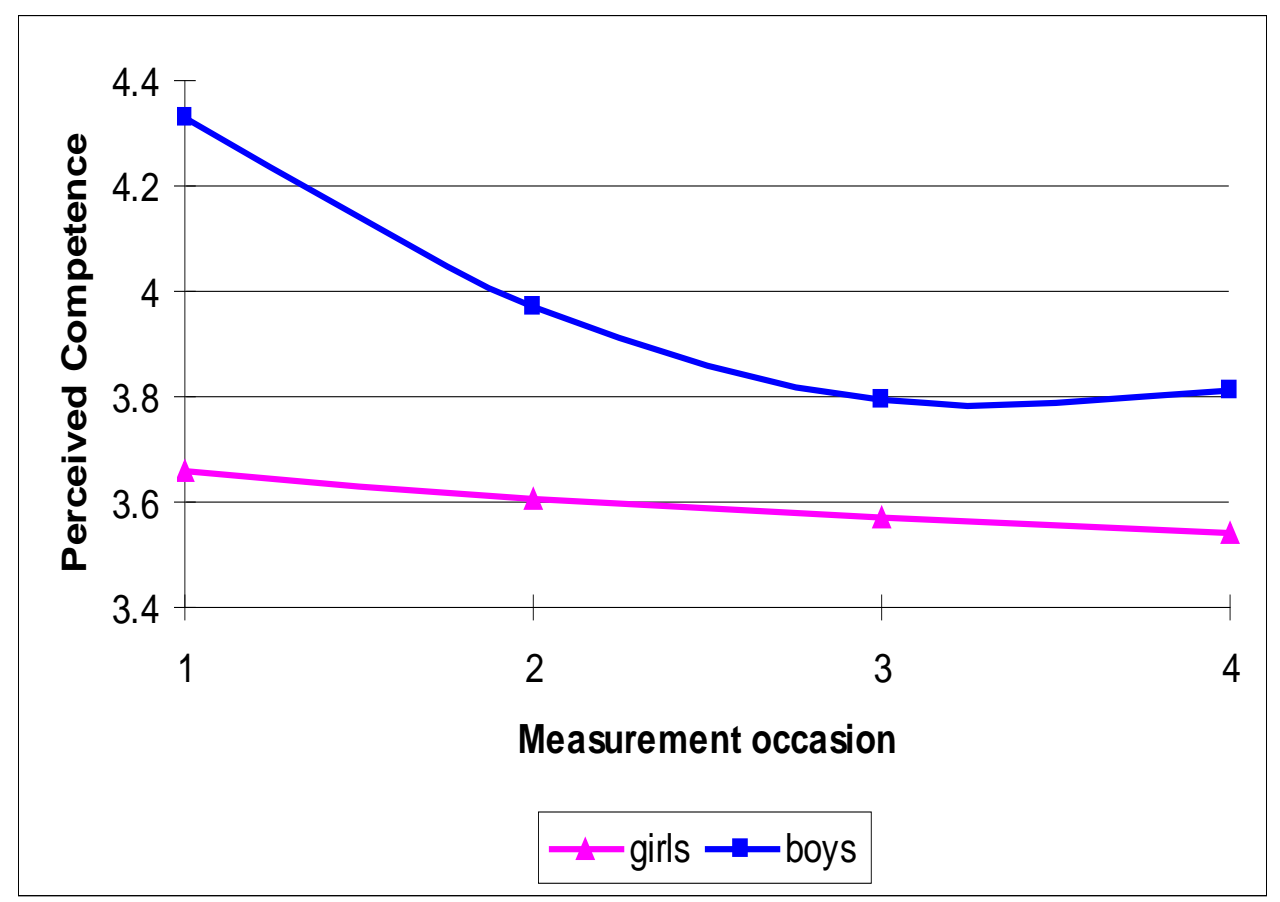

